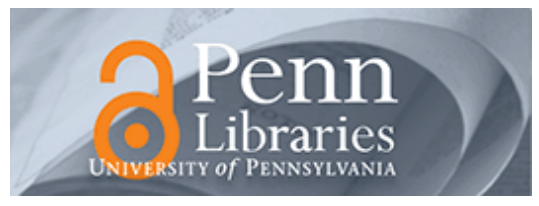

University of Pennsylvania

ScholarlyCommons

\title{
Validity of the Dynamic Indicators for Basic Early Literacy Skills as an Indicator of Early Literacy for Urban Kindergarten Children
}

Heather L. Rouse

University of Pennsylvania, rouseh@gse.upenn.edu

John Fantuzzo

University of Pennsylvania, JOHNF@GSE.UPENN.EDU

Follow this and additional works at: https://repository.upenn.edu/gse_pubs

Part of the Early Childhood Education Commons

\section{Recommended Citation}

Rouse, H. L., \& Fantuzzo, J. (2006). Validity of the Dynamic Indicators for Basic Early Literacy Skills as an Indicator of Early Literacy for Urban Kindergarten Children. School Psychology Review, 35 (3), 341-355.

Retrieved from https://repository.upenn.edu/gse_pubs/437 


\title{
Validity of the Dynamic Indicators for Basic Early Literacy Skills as an Indicator of Early Literacy for Urban Kindergarten Children
}

\author{
Abstract \\ behavioral constructs.

\section{Keywords} \\ urban, kindergarten, dynamic \\ Disciplines \\ Early Childhood Education | Education
}

The validity of three subtests of the Dynamic Indicators for Basic Early Literacy Skills (DIBELS) was investigated for kindergarten children in a large urban school district. A stratified, random sample of 330 participants was drawn from an entire cohort of kindergarten children. Letter Naming Fluency, Phoneme Segmentation Fluency, and Nonsense Word Fluency evidenced significant concurrent and predictive validity when compared to general reading ability measured by teacher report, individual assessments, and group-administered nationally standardized tests. Evidence for convergent and discriminant validity was also found when comparing these subtests to measures of specific literacy, cognitive, and social- 


\title{
Validity of the Dynamic Indicators for Basic Early Literacy Skills as an Indicator of Early Literacy for Urban Kindergarten Children
}

\author{
Heather L. Rouse and John W. Fantuzzo \\ University of Pennsylvania
}

\begin{abstract}
The validity of three subtests of the Dynamic Indicators for Basic Early Literacy Skills (DIBELS) was investigated for kindergarten children in a large urban school district. A stratified, random sample of 330 participants was drawn from an entire cohort of kindergarten children. Letter Naming Fluency, Phoneme Segmentation Fluency, and Nonsense Word Fluency evidenced significant concurrent and predictive validity when compared to general reading ability measured by teacher report, individual assessments, and group-administered nationally standardized tests. Evidence for convergent and discriminant validity was also found when comparing these subtests to measures of specific literacy, cognitive, and social-behavioral constructs.
\end{abstract}

No Child Left Behind legislation has pressed public school administrators to ensure that all children are reading on target by Grade 3 (U.S. Department of Education, 2001). This legislation was designed to address persistently low reading proficiency rates of fourth-grade students in the United States. Under the provisions of this act, school districts are being held accountable on the condition of their success in meeting annual assessment standards. In response, education systems have been forced to answer two critical questions: How will we determine which children are at risk for not meeting the assess- ment standards, and how will intervention be implemented as a function of identified needs? These questions underscore the need for highquality, evidence-based identification and intervention techniques.

In recent years, the science of early childhood has underscored the substantial effect of early childhood experiences on later academic success. National reports have highlighted early childhood as a critical time for skill development and emphasized the centrality of early literacy as foundational to later success (National Research Council, 1998, 2001, 2002). Unfortunately, young children

This research project was supported by a grant from the William Penn Foundation. Thanks goes to Ronnie Bloom and her Foundation staff for their support and sincere interest in this research. Special thanks go to our collaborators at Office of Early Childhood Education in the School District of Philadelphia; this includes Donna Piekarski and Dr. Stephanie Childs.

This article was reviewed and processed during Susan Sheridan's editorial term.

Correspondence regarding this article should be addressed to John Fantuzzo, Graduate School of Education, University of Pennsylvania, 3700 Walnut St., Psychology in Education-314, Philadelphia, PA 19104; e-mail: johnf@gse.upenn.edu

Copyright 2006 by the National Association of School Psychologists, ISSN 0279-6015 
exposed to risk factors associated with poverty and urban environments are less likely to develop early literacy skills and more likely to evidence reading difficulties throughout elementary and secondary school (Duncan \& Brooks-Gunn, 2000; Juel, 1988; Stipek \& Ryan, 1997). The 2000 National Assessment of Educational Progress found that only 14\% of fourth-grade students eligible for the free or reduced-cost lunch program performed at or above the proficient reading level in comparison to $41 \%$ of noneligible students (U.S. Department of Education, National Center for Education Statistics, 2000).

Urban environments are host to a variety of additional structural and social risk factors, such as density of poverty and unemployment, inadequate housing, community violence, and school truancy, that are documented as having negative relationships with school achievement (Garbarino, 1995; Leventhal \& BrooksGunn, 2000). The 2000 National Assessment of Educational Progress exposed a significant reading achievement gap between fourthgrade students in urban public schools as compared to their peers attending urban fringe or large town schools and rural or small town schools (U.S. Department of Education, National Center for Education Statistics, 2001). This risk associated with urban public schools is further exacerbated by an increased likelihood of concentrated poverty within these schools. Enrollment in schools with a high density of poverty has been shown to evidence a unique relationship with school achievement, beyond the individual poverty levels of a child's family (National Research Council, 1998). Research studies exploring the collective effect of these risks, such as the Early Childhood Longitudinal Study-kindergarten cohort, further indicate that as the number of risk factors increase, children evidence slower progress in reading achievement from kindergarten through third grade (U.S. Department of Education, 2004).

State departments of education are now recognizing kindergarten as a critical entry point into public school. As increasing numbers of children enroll in full-day kindergarten programs, schools are pressed to adopt assess- ment and screening methods for young children that are connected to intervention and curricula. A survey of state education departments conducted by the National Center for Education Statistics revealed that whereas only one-third of states use a statewide screening or assessment instrument for incoming kindergarten children, nearly half of local districts assess children's preacademic skills before school entry (Prakash, West, \& Denton, 2003). Over half of these schools use early assessments to inform classroom instruction as children enter school. However, a review of the existing early assessments has drawn attention to the questionable psychometric properties of most of these instruments, most troubling of which is their low predictive validity (Bordingnon \& Lam, 2004). Evidence-based assessment and screening techniques are needed to support districts in meeting the federal mandates of No Child Left Behind (National Institutes of Health \& National Institute of Mental Health, 1998; U.S. Department of Health and Human Services, 2002).

National research panels have identified characteristics of quality early reading assessments to inform instruction. Psychometrically sound assessment instruments (i.e., those with demonstrated reliability and construct and predictive validity) should include an evaluation of specific skills that are amenable to intervention, such as phonological awareness and alphabetic skills (Meier, \& Sullivan, 2004; Meisels \& Atkins-Burnett, 2000). To evaluate the effectiveness of curricula across school districts, we need measures that are sensitive to change over time (Horm-Wingerd, Winter, \& Plotchan, 2001) and ones that can be administered on a large scale in a cost-effective manner (National Research Council, 1998). Early reading instruments that evidence these qualities could be used to screen young children as they enter elementary school and to monitor students' progress across time (Institute for the Development of Educational Achievement, 2002).

The Reading First Assessment Committee recommended the Dynamic Indicators of Basic Early Literacy Skills (Good \& Kaminski, 1996; Kaminski \& Good, 1996) as one 
such quality instrument for children in kindergarten through third grade (Institute for the Development of Educational Achievement, 2002). As of the 2004-2005 school year, more than 2,200 school districts from 49 states and Canada had adopted the DIBELS as a screening tool since this recommendation (Official DIBELS Home Page, retrieved March 30, 2005). The DIBELS contains a set of 10 brief, individually administered tests for kindergarten through third-grade children. It is designed to identify children with early reading difficulty and to monitor progress within the curriculum. Each individual subtest is a short (1-3 min) fluency measure developed from the essential early literacy domains as discussed in both the National Reading Panel (2000) and National Research Council (1998) reports. They include measures of phonological awareness, knowledge of alphabetic print, and language development. These are broken down into grade-appropriate subtests for five indicators: Initial Sound Fluency, Letter Naming Fluency, Phoneme Segmentation Fluency, Nonsense Word Fluency, and Oral Reading Fluency. Three subtests are used for children at the end of kindergarten: Letter Naming Fluency, Phoneme Segmentation Fluency, and Nonsense Word Fluency. Administration of these subtests does not require intensive training, and can be done by regular school personnel (Good et al., 2002). These brief tasks allow for quick identification of ability levels as well as frequent administration throughout the year, and provide information to inform classroom-based intervention (Good \& Shinn, 1990; Kaminski \& Good, 1998).

The DIBELS unpublished technical report provides initial reliability and validity estimates for the subtests used in kindergarten (Good et al., 2002). The authors used samples of children from one school district in the Northwest. By using multiple cohorts of students across four academic school years, sample sizes for each reliability and validity estimate ranged from 37 to 298 , depending on enrollment and attrition. The specific gender and ethnic distribution of each sample was unknown; however, students in the entire school district were reported as approximately
$88 \%$ White, $7 \%$ Latino, 3\% Asian, and 1\% each African American and Native American. This unpublished report provides alternateform and test-retest reliability estimates for each subtest. Concurrent and predictive validity was also demonstrated with global readiness and reading subtests from the WoodcockJohnson Psycho-Educational Battery-Revised.

There are three research articles published in peer-reviewed journals that provide additional psychometric information on the reliability and validity of the DIBELS. The development and validation study, conducted by the DIBELS authors, used a small sample of Caucasian children in kindergarten $(n=18)$ and first grade $(n=19)$ in a rural elementary school in the Pacific Northwest (Kaminski \& Good, 1996). Similar to their technical report, alternate-form and split-half reliability estimates were provided. Evidence for the criterion-related validity of the DIBELS with the McCarthy Scales of Children's Abilities, the Metropolitan Readiness Test, and the Stanford Diagnostic Reading Test was provided for kindergarten children. However, fewer significant reliability estimates were found for first-grade children. A second published study by Hintze, Ryan, and Stoner (2003) used a relatively larger sample of kindergarten children $(n=$ 86), $93 \%$ of whom were Caucasian, to provide evidence of the criterion-related validity with the Comprehensive Test of Phonological Processing. A third study conducted in a moderate-sized midwestern city included 75 kindergarten children, $37 \%$ of whom were nonWhite and one-third eligible for free or reduced-cost lunch (Elliott, Lee, \& Tollefson, 2001). Statistically significant reliability and concurrent validity estimates with criterion measures of phonological awareness, standardized achievement, and teacher ratings were found.

This small set of published studies provides initial support for the concurrent construct validity of the DIBELS for kindergarten children. However, the sampling procedures within these studies preclude generalizability of their results to other populations of children, particularly those at risk for reading dif- 
ficulties. Each study includes fewer than 100 children, and there is no evidence of how these small samples are (or are not) representative of the larger populations from which they were drawn. As a result, there is inadequate power to test the validity for important subgroups within the samples. Furthermore, the characteristics of the larger populations from which they sampled prevent these studies from providing external validity for groups of children who are most at risk for early reading difficulties because of poverty, minority status, or urban residence. Given the magnitude of school districts choosing to use the DIBELS, it is imperative that the information gathered from this instrument is reliable and valid for all children, especially those most vulnerable to poor school outcomes.

The purpose of the present study was to conduct an investigation of the validity of three subtests of the DIBELS for kindergarten children in a large urban school district. These three subtests are used at the end of kindergarten: Letter Naming Fluency, Phoneme Segmentation Fluency, and Nonsense Word Fluency. Two major research questions guided this inquiry: (1) What is the relationship between these subtests and standardized scores from nationally normed tests of distinct literacy constructs (i.e., alphabet knowledge, conventions of print, comprehension, and vocabulary); and (2) what is the relationship between these subtests and measures of other cognitive and behavioral competencies? Using a multitrait-multimethod approach (Campbell and Fiske, 1959), it was hypothesized that DIBELS Letter Naming Fluency would evidence the strongest relationships with alphabet knowledge and independent reading abilities. It was further hypothesized that the DIBELS subtests would have significant, but lower, associations with mathematics. Furthermore, it was hypothesized that stronger relationships with cognitive-based measures (i.e., math, competence motivation) and weaker relationships with emotional and behavioral indicators such as play interaction, disruption, and disconnection would provide evidence for the discriminant validity of the DIBELS.

\section{Method}

\section{Participants}

A stratified, random sample of 330 kindergarten children participated in this study. Children were equally distributed between males (49\%) and females, with an average age of 66 months $(S D=3.8)$. Children within classrooms were stratified to be demographically and geographically representative of the entire cohort of 14,803 kindergarten students in the large urban public school district. The sample demographics mirrored those of the entire cohort, with $55 \%$ of the children African American, $17 \%$ Caucasian, $17 \%$ Hispanic, $9 \%$ Asian, and $2 \%$ other. Thirty-one percent of these children qualified for free or reducedcost lunch. All 330 children were individually assessed by research team members. Complete kindergarten DIBELS and Developmental Reading Assessment (DRA) were obtained for 326 children. Teachers returned $90 \%$ of the emotional-behavioral surveys $(n=296)$, and in first grade 285 children were enrolled in the district and tested in the spring.

\section{Measures}

Child and family demographics. Information regarding participant children's date of birth, gender, race, and free or reduced-cost lunch participation were obtained from administrative records within the school district. Children who live in families receiving Temporary Assistance for Needy Families were automatically enrolled in the district free lunch program. Free lunch was used as a low-income indicator.

Early reading. The Test of Early Reading Ability, third edition (TERA-3; Reid, Hresko, \& Hammill, 2001) is a nationally standardized test of reading ability appropriate for children ages 3 years, 6 months, to 8 years, 6 months. It measures alphabet knowledge, knowledge of conventions of print, and construction of meaning from print. In addition to scores for each such area, an overall composite combines the areas in either ageblocked standard score or raw score form. 
Norms are based on a stratified national sample $(N=875)$ configured to the U.S. Census. Reliability is substantial and validity is supported through correlations with established measures of academic achievement and cognitive ability.

The Developmental Reading Assessment (Beaver, 1997) is an individually administered test of reading accuracy, fluency, and comprehension appropriate for use with children in kindergarten through Grade 3. In a one-to-one format, students read from texts within each level, progressing until they are unable to meet accuracy and comprehension thresholds. The overall score on the DRA is an instructional reading level-or the level at which the student can engage in teacher-instructed text. Across all grade levels and reading levels of the DRA, test-retest reliability estimates range from .91 to .99 , and interrater reliability estimates range from .74 to .80 . Criterion-related construct validity has also been established, with coefficients ranging from .65 to .84 when compared to scores on other nationally standardized measures of early reading ability.

The TerraNova, second edition (CTB/ McGraw-Hill, 1997) is a group-administered achievement test considered among the most reliable and valid of all standardized achievement tests; it is also known as the California Achievement Tests, sixth edition. Standard scores are provided across three subtests related to reading: overall reading, vocabulary, and language. The TerraNova was nationally standardized on a stratified sample of 114,312 students (Grades 1-12) from 778 school districts during the fall of 1999 and another 149,798 students (Grades K-12) in the spring of 2000 . Stratification variables included geographic region, urbanicity, socioeconomic status, and special needs. The TerraNova demonstrates acceptable internal consistency, with Kuder-Richardson Formula 20 coefficients for all subtests and total scores ranging from the middle .80 s to .90 s. Extensive validity work has been conducted on the TerraNova. Items were carefully reviewed to ensure adequate content validity, comparisons with the Test of Cognitive Skills, second edition, and with In-
View (CTB/McGraw-Hill, 2001) indicate evidence of construct validity, and correlations between subtests and total scores support criterion-related validity. Further, the publishers plan to correlate the TerraNova with the National Assessment of Educational Progress, the Third International Mathematics and Science Study, and the SAT and ACT. Based on similar studies relating the California Achievement Tests with the SAT and ACT, the publishers expect strong relationships.

Early mathematics. The Test of Early Mathematics Ability, second edition (Ginsburg \& Baroody, 1990) is an individually administered test of early numeracy skills. It offers a broad assessment of both informal early mathematics (concepts of relative magnitude, counting, calculation with objects present) and formal mathematics (reading and writing numbers, number facts, calculation in symbolic form) for children from 3 years to 8 years, 11 months of age. A standardized composite index is provided, which encompasses all subareas measured by the Test of Early Mathematics Ability. The nationwide normative sample conforms to the U.S. Census ( $N=$ $896)$ and shows high internal consistency and test-retest reliability. Criterion validity has been established with standardized tests of school achievement.

Approaches to learning. The Learning Behaviors Scale (McDermott, Green, Francis, \& Stott, 1999) is a 29-item teacher rating scale measuring children's typical learning-related behaviors observed over the past 2 months. Sample items include "says task is too hard without making much effort to attempt it," "accepts new tasks without fear or resistance," and "responds without taking sufficient time to look at the problem or work out a solution." Teachers indicate whether the indicated behavior most often applies, sometimes applies, or doesn't apply. Four reliable and robust learning behavior dimensions are reported for the 29-item scale: competence motivation, attention-persistence, attitude toward learning, and strategy-flexibility. Standard scores are produced for each dimension 
( $m=50, S D=10)$. Validation and reliability (internal consistency, test-retest, and interrater reliability) support are extensive (Buchanan, McDermott, \& Schaefer, 1998; Coolahan, Fantuzzo, Mendez, \& McDermott, 2000; McDermott, Leigh, \& Perry, 2002) and include validity generalization studies for Head Start and for major ethnic minority populations (Schaefer $\&$ McDermott, 1999). Convergent and divergent validity for the scale have been established by correlating the Learning Behaviors Scale dimensions with factors of the Differential Abilities Scales and Adjustment Scales for Children and Adolescents (McDermott, 1993). National standardization of the Learning Behaviors Scale was conducted with a sample of 1,500 children ages 5-17, stratified according to the U.S. Census by age, gender, academic level, ethnicity, family structure, disabling condition, national region, community size, and parent education (McDermott, 1999).

Interactive peer play. The teacher version of the Penn Interactive Peer Play Scale was used to assess peer-play interactions at the end of kindergarten (Fantuzzo \& Hampton, 2000). The Penn Interactive Peer Play Scale contains 32 items designed to differentiate children who demonstrate positive peer relationships from those who are less successful with peers. The teacher version generates a report of play activities at school and within the classroom, encompassing three underlying dimensions of peer play behaviors: play interaction, play disruption, and play disconnection (Coolahan et al., 2000; Fantuzzo, Coolahan, Mendez, McDermott, \& Sutton-Smith, 1998). These unique dimensions yielded alpha coefficients of $.90, .90$, and .89 for the Play Disruption, Play Disconnection, and Play Interaction factors, respectively. Play Interaction consists of items reflecting prosocial play engagement behaviors that are creative, cooperative, and conducive to successful peer negotiations. The remaining two factors incorporate play behaviors that impede successful peer play in a preschool classroom; Play Disruption encompasses children's aggressive and antisocial play behaviors, while Play Disconnection captures withdrawn and avoidant behaviors. Scores on each dimension are in $T$-score format $(M=50, S D=10)$. Internal consistency for the teacher version shows strong reliability for each of the three factors as well as for the measure as a whole. Concurrent validity has been documented using established teacher rating scales, peer nominations, and observations of classroom free play (Fantuzzo et al., 1998).

\section{Procedures}

A stratified, random sample of participants was drawn from across all 172 public elementary schools within the large urban school district. A sample of 40 schools were selected to be representative of the demographic and economic distributions of each region and the district as a whole. Within each school, children were randomly selected from all kindergarten classrooms and stratified to fit the age, gender, racial, and economic distribution of the entire elementary school kindergarten population.

This study involved the collection of six types of data: (a) administrative data including children's birth date, gender, ethnicity, and free or reduced-cost lunch qualification; (b) teacher ratings of social skills and work habits; (c) teacher assessment of early literacy (DRA); (d) staff assessment of early literacy (DIBELS); (e) group-administered reading achievement tests; and (f) individual assessments of early literacy and numeracy skills. Before the start of participant children's kindergarten school year, research team members and district officials met to draft a confidentiality agreement and data collection procedures. The DIBELS is conducted districtwide by a group of trained early childhood staff three times per year, in October, February, and May. The DRA is administered by kindergarten teachers on the same schedule, in October, February, and May. Students were administered the TerraNova group achievement test in April of their first-grade year. Research team members obtained permission from the school district administration to use these sets of administrative records. A team of Master's-level psychology or education graduate students 
were hired and trained to conduct the TERA and Test of Early Mathematics Ability individual child assessments. In the early spring, teachers were contacted to elicit participation in the study. The team of Master's students conducted individual assessments with all participating children late in the spring semester, corresponding to the final DIBELS and DRA assessment schedule within the school district (May). Subsequent to these assessments, teachers completed the Penn Interactive Peer Play Scale and the Learning Behaviors Scale rating scales. At the end of students' firstgrade year, DRA and TerraNova results were obtained from administrative databases (both administered in April-May of first grade).

\section{Data Analysis}

The nature of the bivariate relationships between subtests of the kindergarten DIBELS and early literacy, mathematics, social, and behavioral outcomes were examined. To explore the multivariate relationships between the DIBELS and other concurrent competencies, canonical correlation analyses were conducted. Through canonical analyses, complex relationships between multivariate domains were examined to determine the divergent and convergent relationships between the two sets of variables (Weiss, 1972). When a significant canonical correlation was found, the canonical structure was examined to understand how the variables are related to each other. High loadings $(\geq .50)$ within the structure denote the strength of a particular variable as contributing to the multivariate relationship between the two sets of constructs. The nature of the relationships was therefore best explained through examining the pattern of loadings on the canonical structure for significant variate pairs and determining the amount of variance shared between these multivariate pairs.

Relationships between kindergarten DIBELS and first-grade outcomes were first explored through bivariate correlations. The amount of variance in first-grade outcomes that could be explained by kindergarten DIBELS scores was examined through simultaneous multiple regression. This analysis al- lowed researchers to look at the overall strength of DIBELS subtests as predictors of reading, vocabulary, and language outcomes. In addition, individual beta weights provided descriptive information about the relative contribution of each DIBELS subtest when considered simultaneously with the other subtests.

\section{Results}

\section{Convergent and Discriminant Validity}

Bivariate correlations between kindergarten DIBELS subtests and standardized tests of early reading provide evidence for concurrent, convergent validity. As expected, Table 1 shows significant positive relationships between each DIBELS subtest and each early literacy construct. Each DIBELS subtest demonstrated the strongest relationship with the DRA instructional reading level. The strongest correlations with TERA subtests were found between each DIBELS subtest and alphabet knowledge.

Canonical variance analysis was conducted to test the significance of the overall multivariate relationship between literacy constructs, examine the nature of the relationship, and determine the amount of variance shared between these multivariate pairs. The findings indicated a significant multivariate relationship between dimensions of early reading skills as measured by the TERA and basic early literacy skills on the DIBELS (Wilks's lambda $=0.58, F[9,779]=21.50, p<$ $.0001)$. This bimultivariate relationship was defined by one significant canonical variate pair, Early Literacy Competence $(R c=.34)$. This variate pair revealed a strong, significant relationship between Alphabet Knowledge, Conventions of Print, and Meaning from Print dimensions of the TERA and the three subtests measured by the DIBELS. Although all three dimensions of the DIBELS were significantly related to this variate pair, the strongest relationship was with Letter Naming Fluency, followed by Nonsense Words and Phoneme Segmentation, respectively (see Table 2 ). Similarly, the strongest relationship to this variate pair from the TERA subscales was found with Alphabet Knowledge, followed by Conven- 
Table 1

Bivariate Correlations With Kindergarten and First-Grade Outcomes

\begin{tabular}{|c|c|c|c|}
\hline \multirow[b]{2}{*}{ Variables } & \multicolumn{3}{|c|}{ DIBELS (Local Percentiles) } \\
\hline & $\begin{array}{l}\text { Letter } \\
\text { Naming } \\
\text { Fluency }\end{array}$ & $\begin{array}{l}\text { Nonsense } \\
\text { Word } \\
\text { Fluency }\end{array}$ & $\begin{array}{c}\text { Phoneme } \\
\text { Segmentation } \\
\text { Fluency }\end{array}$ \\
\hline \multicolumn{4}{|c|}{ Concurrent kindergarten cognitive outcomes ${ }^{\mathrm{a}}$} \\
\hline DRA Instructional Reading & $.62 * *$ & $.62 * *$ & $.48^{* *}$ \\
\hline TERA Reading Quotient & $.52 * *$ & $.53^{* *}$ & $.43^{* *}$ \\
\hline TERA Alphabet & $.59 * *$ & $.56 * *$ & $.47^{* *}$ \\
\hline TERA Conventions & $.41 * *$ & $.44^{* *}$ & $.36^{* *}$ \\
\hline TERA Meaning & $.32 * *$ & $.35 * *$ & $.31 * *$ \\
\hline TEMA Math Quotient & $.56^{* *}$ & $.51 * *$ & $.41^{* *}$ \\
\hline \multicolumn{4}{|c|}{ Concurrent kindergarten behavioral outcomes ${ }^{\mathrm{b}}$} \\
\hline LBS Competence Motivation & $.52 * *$ & $.45^{* *}$ & $.38 * *$ \\
\hline LBS Persistance & $.49 * *$ & $.35^{* *}$ & $.28 * *$ \\
\hline LBS Attitude & $.43^{* *}$ & $.37^{* *}$ & $.31^{* *}$ \\
\hline LBS Strategy & $.33 * *$ & $.23 * *$ & $.21 *$ \\
\hline PIPPS Play Disruption & $-.21 *$ & $-.17 *$ & -.10 \\
\hline PIPPS Play Disconnection & $-.30 * *$ & $-.24 * *$ & $-.24 * *$ \\
\hline PIPPS Play Interaction & $.34 * *$ & $.21^{*}$ & $.17^{*}$ \\
\hline \multicolumn{4}{|l|}{ Predictive first-grade outcomes ${ }^{\mathrm{c}}$} \\
\hline DRA Instructional Reading & $.67^{* *}$ & $.63^{* *}$ & $.55^{* *}$ \\
\hline TerraNova Reading & $.48 * *$ & $.50^{* *}$ & $.49 * *$ \\
\hline TerraNova Vocabulary & $.63^{* *}$ & $.57 * *$ & $.50 * *$ \\
\hline TerraNova Language & $.57^{* *}$ & $.55^{* * *}$ & $.53^{* *}$ \\
\hline \multicolumn{4}{|c|}{$\begin{array}{l}\text { Note. DIBELS = Dynamics Indicators of Basic Early Literacy Skills; DRA = Developmental Reading Assessment; } \\
\text { TERA = Test of Early Reading Ability; TEMA = Test of Early Mathematics Ability; LBS = Learning Behaviors Scale; } \\
\text { PIPPS = Penn Interactive Peer Play Scale. } \\
{ }^{a} N=33 . \\
{ }^{b} N=298 . \\
{ }^{c} N=288 . \\
{ }^{* *} p<.0001 . \\
{ }^{*} p<.01 .\end{array}$} \\
\hline
\end{tabular}

tions of Print and Meaning from Print, respectively. Redundancy analysis demonstrated that the TERA dimensions explained $31 \%$ of the variance in the DIBELS subtests, whereas the DIBELS represented $25 \%$ of the variance in the TERA dimensions.

Discriminant validity was demonstrated using measures of children's social and behavioral skills. Significant negative bivariate relationships were found between DIBELS subtests and two dimensions of interactive peer-play difficulties, Play Disruption and Play Disconnection (see Table 1). Conversely, positive relation- ships were found between DIBELS and measures of children's prosocial engagement and behavioral approaches to learning. As hypothesized, these significant correlations were less strong than those found for the cognitive and language dimensions. Within the approaches to learning constructs, Competence Motivation was found to have the strongest relationship with early literacy subtests.

Canonical variance analysis indicated a significant bimultivariate relationship between peer-play dimensions of the Penn Interactive Peer Play Scale, learning behavior dimensions 
Table 2

Canonical Structure of the TERA With the DIBELS

\begin{tabular}{ll}
\multicolumn{1}{c}{ Variable } & $\begin{array}{c}\text { Canonical Variate Set: } \\
\text { Early Literacy Competence }\end{array}$ \\
\hline TERA & $\mathbf{9 8}$ \\
Alphabet Knowledge & .71 \\
Conventions of Print & .56 \\
Meaning From Print & .93 \\
DIBELS & .89 \\
Letter Naming Fluency & .73 \\
Nonsense Word Fluency & .73 \\
Phoneme Segmentation Fluency &
\end{tabular}

Note. TERA $=$ Test of Early Mathematics Ability; DIBELS = Dynamic Indicators of Basic Early Literary Skills. $N=326$.

of the Learning Behaviors Scale, and the DIBELS subtests measured at the end of the kindergarten year (see Table 3; Wilks's lambda $=0.64, F[21,802]=6.37, p<$ $.0001)$. One significant bimultivariate relationship emerged, yielding one variate pair: Engaged Literacy Learning $(R c=.26)$. This variate pair indicated a positive relationship between Play Interaction and the Letter Naming, Nonsense Words, and Phoneme Segmentation Fluency subtests of the DIBELS, and a negative relationship between Play Disconnection and the DIBELS subtests. Redundancy analysis demonstrated that while the social and behavioral dimensions explained $14 \%$ of the variance in the DIBELS subtests, the DIBELS accounted for $21 \%$ of the variance in the social and behavioral dimensions.

\section{Predictive Validity}

Significant predictive relationships were found between early literacy skills measured by the DIBELS in kindergarten and literacy constructs at the end of first grade. Table 1 shows that the DIBELS subtests had the strongest bivariate association with first-grade instructional reading levels measured by the DRA. Simultaneous multiple regression analyses revealed a significant overall relationship between DIBELS subtests and first-grade instructional reading
$(F[3,284]=101.22, p<.0001)$. As indicated by the $R^{2}$, DIBELS subtests at the end of kindergarten explained $51.9 \%$ of the variance in first-grade instructional reading. Of the three DIBELS subtests, Letter Naming Fluency (standard regression coefficient $=.45, p<.0001$ ) had the strongest association with reading at the end of the year. Table 4 presents the results of these analyses.

Significant bivariate relationships were also found between DIBELS and each TerraNova subtest in first grade. Table 1 indicates relatively stronger predictive relationships between DIBELS subtests and Vocabulary, followed by Language and Reading, respectively. Regression of the DIBELS in kindergarten on the Vocabulary dimension of the TerraNova at the end of the year resulted in a significant overall relationship $(F[3,277]$ $=75.04, p<.0001$; see Table 4). DIBELS dimensions accounted for $45.1 \%$ of the variance in Vocabulary. Letter Naming Fluency (standard regression coefficient $=.46, p<$ .0001 ) emerged as the strongest predictor of vocabulary, followed by Phoneme Segmentation Fluency. Nonsense Word Fluency was not a significant predictor.

When DIBELS scores were regressed onto the Language dimension of the TerraNova, the equation was significant $(F[3,285]=65.31$, $p<.0001)$. Overall, the $R^{2}$ suggests that $41 \%$ of 
Table 3

Canonical Structure of the PIPPS and LBS With the DIBELS

\begin{tabular}{lc}
\multicolumn{1}{c}{ Variable } & $\begin{array}{c}\text { Canonical Structure Coefficients: } \\
\text { Engaged Literacy Learning }\end{array}$ \\
\hline PIPPS & \\
Play Interaction & .59 \\
Play Disruption & -.33 \\
Play Disconnection & -.50 \\
LBS & .94 \\
Competence Motivation & .85 \\
Attention-Persistence & .76 \\
Attitude Toward Learning & .57 \\
Strategy-Flexibility & .99 \\
DIBELS & .76 \\
Letter Naming Fluency & .61 \\
Nonsense Word Fluency & \\
Phoneme Segmentation Fluency &
\end{tabular}

Note. PIPPS = Penn Interactive Peer Play Scale; LBS = Learning Behavior Scale; DIBELS $=$ Dynamic Indicators of Basic Literacy Skills.

$N=289$.

the variance in Language is explained by the DIBELS. Of the three TerraNova dimensions, Letter Naming Fluency (standard regression coefficient $=.36, p<.0001$ ) held the strongest relationship with Language, followed by Phoneme Segmentation Fluency. Nonsense Word Fluency was not significant. A similar pattern was found for TerraNova Reading outcomes. Simultaneous multiple regression revealed a significant overall relationship between DIBELS and Reading $(F[3,285]=43.88, p<.0001)$. Letter Naming Fluency and Phoneme Segmentation Fluency were significant predictors of Reading, but Nonsense Word Fluency was not significant. DIBELS subtests explained $32 \%$ of the variance in Reading.

\section{Discussion}

The present study provided a multitraitmultimethod examination of the validity of the DIBELS for a representative sample of kindergarten students from a large urban school district. The school district's kindergarten population, which is primarily comprised of low-income minority students, provides a policyrelevant test of this measure. Convergent and discriminant validity was assessed for three kindergarten literacy indicators of the DIBELS. Letter Naming, Nonsense Words, and Phoneme Segmentation fluency were found to have the strongest positive relationships with indicators of overall reading ability (i.e., DRA instructional reading and TERA Reading Quotient). This finding corroborates previous research with these DIBELS constructs documenting criterionrelated validity with standardized assessments of overall reading ability (e.g., Elliot, Lee, \& Tollefson, 2001; Good, Kaminski, Simmons, \& Kame'enui, 2001; Kaminski \& Good, 1996).

The current findings add to this research by demonstrating convergent and discriminant validity using specific literacy constructs. As hypothesized, face validity of the DIBELS was demonstrated by finding that the subtests were convergent with similar literacy constructs and divergent with less similar constructs. Alphabet Knowledge evidenced the strongest concurrent relationship with Letter Naming Fluency, and vice versa. As would be expected according to the convergent-discriminant hypothesis, Letter Naming Fluency was less related to the other literacy con- 


\section{Table 4}

\section{Summary of Simultaneous Regression Analyses for DIBELS Subtests Predicting First-Grade Standardized Reading Outcomes}

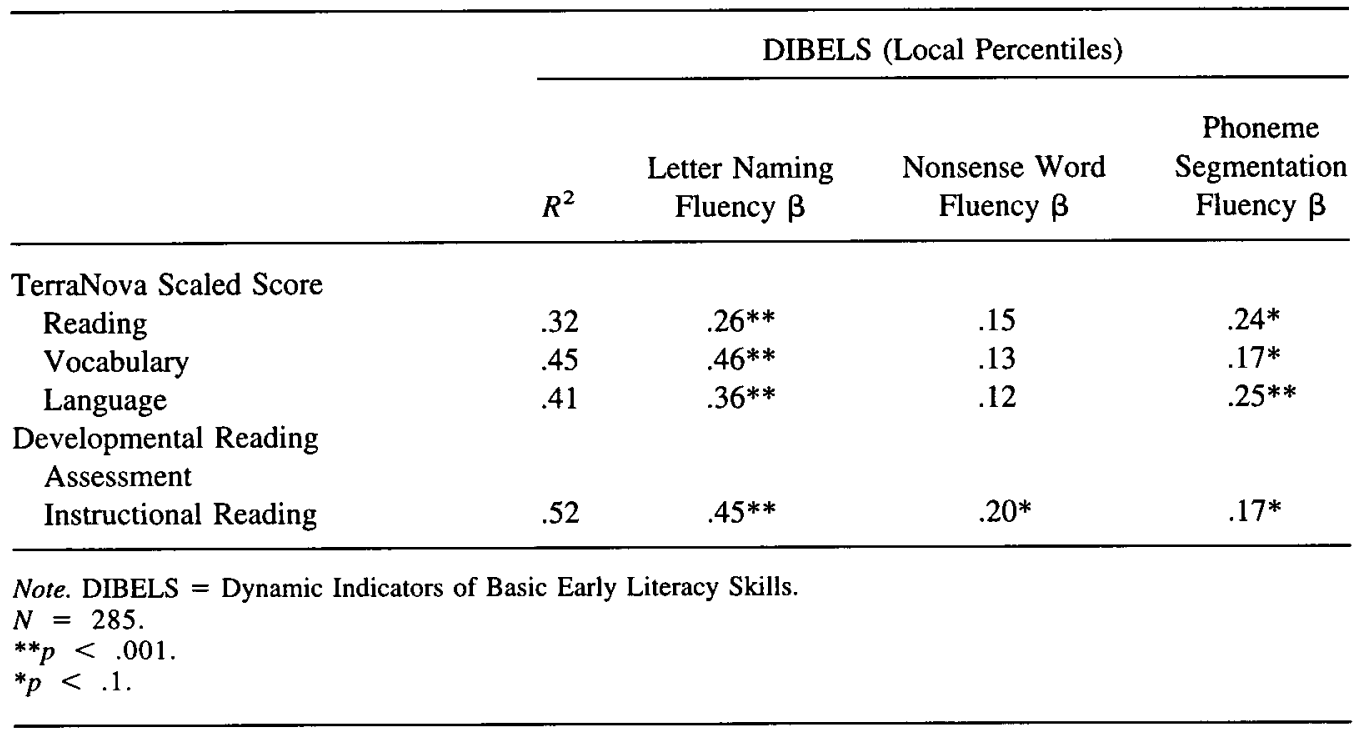

structs. A similar pattern was found with Nonsense Word Fluency. This subtest measures children's ability to apply basic early literacy principles (e.g., decoding, left-to-right) to the novel task of reading nonsense words. Conventions of Print, a direct assessment of children's knowledge of the process and basic principals of learning to read, demonstrated the strongest relationship to Nonsense Word Fluency. These findings uphold the convergent-divergent hypothesis using multiple methods (i.e., teacher evaluation and individual assessment), providing support for the distinctiveness of each literacy construct measured by the DIBELS.

The use of specific literacy constructs uniquely contributes to the current DIBELS validity literature. Previous research has demonstrated concurrent validity in kindergarten using overall reading ability assessments or specific measures of phonological awareness (Elliott et al., 2001; Hintze et al., 2003). These studies, however, did not include other primary literacy constructs that are similar to Letter Naming or Nonsense Words. DIBELS authors have provided some validity evidence, but a similar limitation exists; validity was established in kinder- garten using general intelligence measures, reading and math achievement, and overall reading fluency (Good et al., 2001; Kaminski \& Good, 1996). The current study is the first to explore the validity of Letter Naming, Nonsense Words, and Phoneme Segmentation fluency administered in kindergarten with measures of specific literacy constructs (i.e., Alphabet Knowledge, Conventions of Print, and Meaning From Print).

Predictive validity evidence for the DIBELS was also found. Significant relationships were demonstrated with reading, vocabulary, and language constructs measured at the end of first grade. Letter Naming, Nonsense Words, and Phoneme Segmentation correlated significantly to each of these outcomes in first grade. However, Letter Naming evidenced the largest correlation coefficients, followed closely by Nonsense Words. These results echo similar early literacy research highlighting the predictive utility of children's ability to identify letter names and sounds (Schatschneider, Francis, Carlson, Fletcher, \& Foorman, 2004). In a comprehensive review of research on early predictors of later reading skills, Scarborough (1998) found that the best individual predictor of reading involved print-spe- 
cific knowledge, such as letter naming and concepts of print. In contrast, research has also pointed to phonological awareness as the strongest predictor of later reading ability (Shankweiler et al., 1999). The primary limitation of this previous research, however, is that it has not explored early literacy constructs simultaneously (Blaiklock, 2004). The conceptual and developmental overlap between specific early literacy skills necessitates a research process that captures the multidimensionality of children's reading competence.

The current study contributes to this debate by demonstrating the unique predictive relationship between early letter naming ability and later reading competencies, while concurrently controlling for the variance associated with phonological skills and print conventions. Simultaneous regression analyses revealed Letter Naming to be the most significant predictor of first-grade reading, vocabulary, and language. Phoneme Segmentation emerged as the second strongest predictor. In contrast to findings from the univariate correlational analyses, simultaneous consideration of these constructs vitiated the relationships between Nonsense Words and later reading outcomes. In sum, by using a multivariate approach, the unique contribution of both alphabet knowledge and phonological awareness to reading ability was demonstrated. Findings also suggest that when examined simultaneously with alphabetic principles and phonological awareness, the ability to fluently read nonsense words does not provide unique predictive information about later reading competency.

The inclusion of first-grade reading level, vocabulary, and language constructs to determine the predictive validity of the DIBELS provides another distinctive contribution to the validity literature. Previously published research has demonstrated predictive relationships between Letter Naming, Nonsense Words, and Phoneme Segmentation with standardized tests of overall reading ability (Kaminski \& Good, 1996). This is the first study, however, to demonstrate predictive validity for each subtest with individual assessments of unique literacy constructs. Firstgrade vocabulary, reading level and word fluency, and comprehension of language principles are known predictors of later school achievement (Dickinson \& Tabors, 2001; Scarborough, 2001). The significant longitudinal relationships found between alphabetic principles and phonemic awareness and these first-grade constructs emphasize the importance of early skill development. Children who experience early difficulty in visual or auditory identification of letters, for example, may be less equipped to develop future literacy skills such as vocabulary and the ability to comprehend written text.

Convergent and divergent validity analyses also confirmed the hypothesized relationships between literacy constructs and other cognitive competencies. Children's early mathematics ability was significantly related to Letter Naming, Nonsense Words, and Phoneme Segmentation Fluency. This convergent finding supports the proposition that global dimensions of cognitive ability will relate significantly to one another and is well documented in the early childhood development literature. Specifically, previous research has highlighted the integrated nature of early language and cognitive development, and the bidirectional influence of early developmental competencies (National Research Council, 1998).

Relationships were also found between early literacy and social-behavioral constructs, though they demonstrated less convergence than when compared to mathematics. The hypothesized positive relations between early literacy and children's peer play competence, task persistence, competence motivation, and task flexibility were supported by the study findings. Peer interaction during free play was significantly related to Letter Naming, Nonsense Words, and Phoneme Segmentation, although the amount of shared variance between these constructs was minimal $\left(R^{2}\right.$ $=.03-.11$ ). Significant associations were also found between early literacy and behavioral approaches to learning (i.e., competency motivation, task persistence, flexibility, and attitude toward learning).

These convergent and divergent validity findings underscore the important developmental overlap among cognitive and behav- 
ioral competencies for young children. Early childhood researchers have documented the integrated nature of early skill development, particularly with respect to the multitude of skills necessary to develop competent reading abilities (Storch \& Whitehurst, 2001; Whitehurst \& Lonigan, 1998). This study contributes to this literature by using a multivariate approach to highlight the unique contributions of specific literacy constructs to overall reading ability. Furthermore, the overlap between social-behavioral competencies and literacy development for young children is also demonstrated in this study. Specifically, the pattern of correlations among these variables denotes the importance of children's engagement behaviors in creating cognitive linkages to literacy learning. Children's engagement behaviors within the classroom (with peers or specific tasks) were stronger predictors of acquired literacy skills than other, more emotionally based behavior (e.g., play disruption or attitude toward learning). This contributes to the existing early childhood literature that underscores the significant relationships between children's engagement in the classroom and the development of cognitive competencies (Dickinson \& McCabe, 2001; Fantuzzo, Perry, \& McDermott, 2004; McWayne, Fantuzzo, \& McDermott, 2004).

Findings from this research are qualified to urban public school kindergarten children. As such, this research provides support for the use of DIBELS as a screening tool for this population. The three subtests recommended for the end of kindergarten could be used to guide classroom-based instruction and intervention. The short, fluency-based nature of the instrument supports its utility in measuring progress and response to classroom-based intervention. The predictive validity findings also underscore the utility of this measure in providing a reliable and valid means for identifying early reading difficulties. Teachers could use the DIBELS to identify children who are not on target for meeting national mandates and adapt curricular efforts to target specific early literacy skills with which children are having the most difficulty.

This study contributes to the burgeoning literature on the DIBELS; however, further research needs to be conducted with other populations of children and across different grade levels. The current study sample did not allow for the exploration of validity for English language learners-future research should investigate validity for this significant population of young children. In addition to the three indicators used at the end of kindergarten, the DIBELS contain two additional subtests: Initial Sound Fluency and Oral Reading Fluency. Initial Sound Fluency is used in the fall and winter of kindergarten, and Oral Reading Fluency begins in the middle of first grade and extends to the end of third grade. Future research should explore the convergent and divergent validity for each of the DIBELS subtests administered at each grade level.

The federal legislation pertaining to No Child Left Behind is pressing educators toward evidence-based, culturally appropriate decision making to ensure that all children are reading on grade level. This mandate has heightened the need for early intervention, and subsequently the need for assessment instruments of high quality with the ability to identify children's ability levels before third grade. As increasing numbers of school districts are selecting early literacy screening instruments, evidence for the psychometric properties of these measures must be developed. All children across the country are being held to higher standards of competency. This study provided validity evidence for one policy-relevant population: low-income, predominately minority children attending public school in a large urban district. To justly leave no child behind, however, additional research is needed to validate early literacy indicators such as the DIBELS with other vulnerable populations of young children.

\section{References}

Beaver, J. (1997). Developmental reading assessment, $K-3$. Glenview, IL: Celebration Press.

Blaiklock, K. E. (2004). The importance of letter knowledge in the relationship between phonological awareness and reading. Journal of Research in Reading, 27(1), 36-57.

Bordingnon, C. M., \& Lam, T. C. M. (2004). The early assessment conundrum: Lessons from the past, implications for the future. Psychology in the Schools, 4I(7), 737-749. 
Buchanan, H. H., McDermott, P. A., \& Schaefer, B. A. (1998). Agreement among classroom observers of children's stylistic learning behaviors. Psychology in the Schools, 35(4), 355-362.

Campbell, D. T., \& Fiske, D. W. (1959). Convergent and discriminant validation by the multitrait-multimethod matrix. Psychological Bulletin, 56(2), 81-105.

Coolahan, K. C., Fantuzzo, J., Mendez, J., \& McDermott, P. A. (2000). Preschool peer interactions and readiness to learn: Relationships between classroom peer play and learning behaviors and conduct. Journal of Educational Psychology, 92, 458-465.

CTB/McGraw-Hill. (1997). TerraNova. Monterey, CA: Author.

CTB/McGraw-Hill. (2001). InView. Monterey, CA: Author.

Dickinson, D. K., \& McCabe, A. (2001). Bringing it all together: The multiple origins, skills, and environmental supports of early literacy. Learning Disabilities Research \& Practice, 16(4), 186-202.

Dickinson, D. K., \& Tabors, P. O. (2001). Beginning literacy with language: Young children learning at home and school. Baltimore, MD: Paul H. Brookes Publishing.

Duncan, G. J., \& Brooks-Gunn, J. (2000). Family poverty, welfare reform, and child development. Child Development, $71(1)$, 188-196.

Elliott, J., Lee, S. W., \& Tollefson, N. (2001). A reliability and validity study of the Dynamic Indicators of Basic Early Literacy Skills-Modified. School Psychology Review, 30(1), 33-49.

Fantuzzo, J., Coolahan, K. C., Mendez, J. L., McDermott, P. A., \& Sutton-Smith, B. (1998). Contextually-relevant validation of constructs of peer play with African American Head Start children: Penn Interactive Peer Play Scale. Early Childhood Research Quarterly, 13(3), 411-431.

Fantuzzo, J. W., \& Hampton, V. R. (2000). Penn Interactive Peer Play Scale: A parent and teacher rating system for young children. In K. Gitlin-Weiner, A. Sandgrund, \& C. Schaefer (Eds.), Play diagnosis and assessment (2nd ed., pp. 599-620). New York: Wiley.

Fantuzzo, J., Perry, M. A., \& McDermott, P. (2004). Preschool approaches to learning and their relationship to other relevant classroom competencies for low-income children. School Psychology Quarterly, 19(3), 212-230.

Garbarino, J. (1995). Raising children in a socially toxic environment. San Francisco: Jossey-Bass.

Ginsburg, H. P., \& Baroody, A. J. (1990). Test of Early Mathematics Ability (2nd ed.). Austin, TX: Pro-Ed, Inc.

Good, R. H., \& Kaminski, R. A. (1996). Assessment for instructional decisions: Toward a proactive/prevention model of decision-making for early literacy skills. School Psychology Quarterly, 11, 326-336.

Good, R. H., Kaminski, R. A., Simmons, D., \& Kame'enui, E. J. (2001). Using Dynamic Indicators of Basic Early Literacy Skills (DIBELS) in an outcomesdriven model. OSSC Bulletin, 44(1), 1-24.

Good, R. H., Kaminski, R. A., Shinn, M., Bratten, J., Shinn, M., \& Laimon, L. (2002). Assessment committee: Analysis of reading assessment measures. Unpublished technical manual, University of Oregon, Eugene.
Good, R. H., \& Shinn, M. R. (1990). Forecasting accuracy of slope estimates for reading curriculum-based measurement. Behavioral Assessment, 12, 179-193.

Hintze, J. M., Ryan, A. L., \& Stoner, G. (2003). Concurrent validity and diagnostic accuracy of the Dynamic Indicators of Basic Early Literacy Skills and the Comprehensive Test of Phonological Processing. School Psychology Review, 32(4), 541-556.

Horm-Wingerd, D. M., Winter, P. C., \& Plotchan, P. (2001). Primary level assessment for IASA Title I: A call for discussion. Washington, DC: Council of Chief State School Officers.

Institute for the Development of Educational Achievement. (2002). An analysis of reading assessment instruments for $K-3$. Final Report prepared by Edward J. Kame'enui, $\mathrm{PhD}$, Institute for the Development of Educational Achievement, College of Education, University of Oregon.

Juel, C. (1988). Learning to read and write: A longitudinal study of 54 children from first through fourth grades. Journal of Educational Psychology, 80, 437-447.

Kaminski, R. A., \& Good, R. H. (1996). Toward a technology for assessing basic early literacy skills. School Psychology Review, 25, 215-227.

Kaminski, R. A., \& Good, R. H. (1998). Assessing early literacy skills in a problem-solving model: Dynamic Indicators of Basic Early Literacy Skills. In M. R. Shinn (Ed.) Advanced applications of curriculumbased measurement (pp. 113-142). New York: Guilford Press.

Leventhal, T., \& Brooks-Gunn, J. (2000). The neighborhoods they live in: The effects of neighborhood residence on child and adolescent outcomes. Psychological Bulletin, 126(2), 309-337.

McDermott, P. A. (1993). National standardization of uniform multisituational measures of child and adolescent behavior pathology. Psychological Assessment, 5(4), 413-424.

McDermott, P. A. (1999). National scales of differential learning behaviors among American children and adolescents. School Psychology Review, 28(2), 280-291.

McDermott, P. A., Green, L. F., Francis, J. M., \& Stott, D. H. (1999). Learning Behaviors Scale. Philadelphia, PA: Edumetric and Clinical Science.

McDermott, P. A., Leigh, N. M., \& Perry, M. A. (2002). Development and Validation of the Preschool Learning Behaviors Scale. Psychology in the Schools, 39(4), 353-365.

McWayne, C. M., Fantuzzo, J. W., \& McDermott, P. A. (2004). Preschool competency in context: An investigation of the unique contribution of child competencies to early academic success. Developmental Psychology, 40(4), 633-645.

Meier, J., \& Sullivan, A. K. (2004). Spotlight schools: Success stories from high-risk kindergartens. Reading \& Writing Quarterly, 20, 285-304.

Meisels, S. J., \& Atkins-Bumett, S. (2000). The elements of early childhood assessments. In J. P. Shonkoff \& S. J. Meisels (Eds.), Handbook of early childhood intervention (2nd ed., pp. 231-257). Cambridge, UK: Cambridge University Press.

National Institutes of Health \& National Institute of Mental Health (NIMH). (1998). Bridging science and service: A report by the National Advisory Mental Health Council's Clinical Treatment and Services Research Workgroup. Washington, DC: NIMH. 
National Reading Panel. (2000). Teaching children to read: An evidence-based assessment of the scientific research literature on reading and its implications for reading instruction. Washington, DC: National Institute of Child Health and Human Development.

National Research Council. (1998). Preventing reading difficulties in young children. Washington, DC: National Academy Press.

National Research Council. (2001). Eager to learn. Washington, DC: National Academy Press.

National Research Council. (2002). From neurons to neighborhoods. Washington, DC: National Academy Press.

Official DIBELS Home Page. (2005, March 30). Retrieved March 30, 2005, from http://dibels.uoregon.edu

Prakash, N., West, J., \& Denton, K. (2003). Schools' use of assessments for kindergarten entrance and placement: 1998-1999. Education Statistics Quarterly, 5(1), 37-41.

Reid, D. K., Hresko, W. P., \& Hammill, D. D. (2001). Test of Early Reading Ability (3rd ed.). Austin, TX: Pro-Ed, Inc.

Scarborough, H. (2001). Connecting early language and literacy to later reading (dis)abilities: Evidence, theory, and practice. In S. B. Neuman \& D. K. Dickinson (Eds.), Handbook of early literacy research (pp. 97110). New York: Academic Press.

Scarborough, H. S. (1998). Early identification of children at risk for reading disabilities: Phonological awareness and some other promising predictors. In B. K. Shapiro, A. J. Capute, \& B. Shapiro (Eds.), Specific reading disability: $A$ view of the spectrum (pp. 77-121). Hillsdale, NJ: Erlbaum.

Schaefer, B. A., \& McDermott, P. A. (1999). Learning Behavior and Intelligence as Explanations for Children's Scholastic Achievement. Journal of School Psychology, 37, 299-313.

Schatschneider, C., Francis, D. J., Carlson, C. D., Fletcher, J. M., \& Foorman, B. R. (2004). Kindergarten prediction of reading skills: A longitudinal comparative analysis. Journal of Educational Psychology, 96(2), 265-282.

Shankweiler, D., Lundquist, E., Katz, L., Stuebing, K. K., Fletcher, J. M., Brady, S., et al. (1999). Comprehension and decoding: Patterns of association in children with reading difficulties. Scientific Studies of Reading, 3, 69-94.

Stipek, R., \& Ryan, R. H. (1997). Economically disadvantaged preschoolers: Ready to learn but further to go. Developmental Psychology, 33, 711-723.

Storch, S. A., \& Whitehurst, G. J. (2001). The role of family and home in the literacy development of children from low-income backgrounds. In P. R. Britto \& J. Brooks-Gunn (Eds.), The role of family literacy environments in promoting young children's emerging literacy skills. New directions for child and adolescent development (p. 53-71). San Francisco, CA: JosseyBass.

U.S. Department of Education. (2001). No Child Left Behind Act. http://www.ed.gov/nclb

U.S. Department of Education. (2004). The condition of education 2004 (National Center for Education Statistics [NCES] 2004-077). Washington, DC: Government Printing Office.

U.S. Department of Education, National Center for Education Statistics. (2000). America's kindergartners (NCES 2000-070). Washington, DC.

U.S. Department of Education, Office of Educational Research and Improvement, National Center for Education Statistics. (2001). The nation's report card: Fourth-grade reading 2000 (NCES 2001-499). Washington, DC.

U.S. Department of Health and Human Services (DHHS). (2002). Early childhood education and school readiness: Conceptual models, constructs, and measures. Workshop summary, sponsored by U.S. DHHS: National Institute of Child Health and Human Development (NICHD), Administration on Children, Youth, and Families (ACYF), and Office of the Assistant Secretary for Planning and Evaluation (ASPE), June, 2002. Washington, DC.

Weiss, D. J. (1972). Canonical correlation analysis in counseling psychology research. Journal of Counseling Psychology, 19(3), 241-252.

Whitehurst, G. J., \& Lonigan, C. J. (1998). Child development and emergent literacy. Child Development, 69, 848-872.

Date Received: May 4, 2005

Date Accepted: May 3, 2006

Action Editor: Tanya Eckert

Heather Rouse, MSEd, is an advanced doctoral student in the School, Community, and Clinical Child Psychology program at the Graduate School of Education, University of Pennsylvania. She is an Administration for Children and Families (ACF)/Head Start Research Scholar, and her research interests include children's socioemotional development and approaches to learning, kindergarten transition, school readiness, and early childhood public policy.

John Fantuzzo, PhD, is the Diana Riklis Professor of Psychology in Education, in the Policy Research, Evaluation and Measurement Program at the University of Pennsylvania. He is also the Director of Penn CHILD Research (Children's Institute of Learning and Developmental Research). He specializes in the population-based study of risk and protective factors that affect school readiness and early school success for low-income urban children. 
Copyright of School Psychology Review is the property of National Association of School Psychologists and its content may not be copied or emailed to multiple sites or posted to a listserv without the copyright holder's express written permission. However, users may print, download, or email articles for individual use. 